\title{
Effects of recruiting midwives into family physician program on the percentage of low birth weight (LBW) infants in rural areas of Kurdistan
}

\author{
Shayesteh Hajizadeh ${ }^{1}$, Fahimeh Ramezani Tehrani*2, Masoumeh Simbar ${ }^{1}$, Farshad Farzadfar ${ }^{3}$
}

\begin{abstract}
Background: LBW is an important factor that can affect infant mortality and represents an index of economic and social development. It is expected that an increase in the density of midwives attending family physician programs will lead to a decrease in LBW in health centers. This study aimed to compare the percentage of LBW infants before and after the implementation of the family physician program in health centers with and without an increase in midwives density.

Methods: This cross-sectional study compared the percentage of LBW infants before and after the implementation of family physician programs in rural health centers with and without changes in midwives density in Kurdistan. In this study, we included 668 mothers of 2-month-old children and administered structured interviews in 2005 and 2013. Data were analyzed using the difference-indifferences and the Matchit statistical models.

Results: The Matchit model showed a significant average percentage increase $0.08(0.006-0.17)$ in LBW infants born between 2005 and 2013 in health centers where the density of midwives increased compared with those where it remained unchanged. The difference-in-differences model showed that the odds ratio of LBW infants is increased by more than twice among participants who had a history of caesarean section.

Conclusion: The results of this study showed that an increase in the density of midwives in a family physician program did not have an impact on reducing the percentage of LBW infants born between 2005 and 2013, in health centers where the density of midwives augmented compared to those where it remained unaltered; it indicated that the increase in the density of midwives alone was not efficient. On the other hand, the results of our study show an increase in the risk of infants born at a LBW due to caesarean section. It is recommended that obstetricians and gynecologists must strictly control pregnancies and avoid unnecessary termination of pregnancy.
\end{abstract}

Keywords: Low birth weight, Delivery of health care, Outcome assessment, Kurdistan, Iran

Copyright $₫$ Iran University of Medical Sciences

Cite this article as: Hajizadeh Sh, Ramezani Tehrani F, Simbar M, Farzadfar F. Effects of recruiting midwives into family physician program on the percentage of low birth weight (LBW) infants in rural areas of Kurdistan. Med J Islam Repub Iran. 2017(17 Dec);31.91.

https://doi.org/10.14196/mjiri.31.91

\section{Introduction}

Birth weight is one of the most important health indicators of development in every country as one of the main factors for normal growth and development and even survival of newborns and infants (1). LBW is an important factor that can affect infant mortality, with serious consequences during infancy (2), childhood (3) and even adulthood (4).

Corresponding author: Dr Fahimeh R Tehrani, framezan@ post.harvard.edu

1. Midwifery and Reproductive Health Department, Faculty of Nursing and Midwifery, Shahid Beheshti University of Medical Sciences, Tehran, Iran

2. Reproductive Endocrinology Research Center, Research Institute for Endocrine Sciences, Shahid Beheshti University of Medical Sciences, Tehran, Iran

3. Non-communicable Diseases Research Center, Endocrinology and Metabolism Research Institute, Tehran University of Medical Sciences, Tehran, Iran
The risk factors for LBW vary among populations (5), and are also considerably different between term and preterm deliveries. For example, one of the causes of LBW is preterm delivery, which may occur due to an early elective caesarean section followed by maternal or fetal indications (6). Therefore, it is recommended to precisely control pregnancies and prevent unnecessary termination of

$\uparrow$ What is "already known" in this topic:

Several studies have shown the effects of the availability of health care practitioners on improving primary care and basic preventive services.

\section{$\rightarrow$ What this article adds:}

The results of this study showed that an increase in the density of midwives in a family physician program have not improved pregnancy outcomes in term of low birth infant's rate. It indicated that the increase in the density of midwives alone may not be efficient. 
pregnancy (7)

Other factors influencing LBW in newborns are the lack or inadequate prenatal care $(8,9)$. Some studies showed that the socioeconomic status of families and communities represents an important factor in reducing the prevalence of LBW infants $(10,11)$ and other determinants of LBW are smoking (9), low maternal education (12), younger maternal age (13), marital status, slight weight gain during pregnancy, hypertension, genitourinary tract infection in pregnancy, parity, and fewer prenatal consultations (14).

Interventions to reduce the LBW can be classified as primary (directed to all women before or during pregnancy to prevent and reduce risk), secondary (aimed at eliminating or reducing risk in women with known risk factors) (15). Therefore, delivering prenatal care and training pregnant women, particularly those with low socioeconomic status, can be effective in reducing LBW infants and thus decreasing infant mortality (16).

International studies have shown that people's access to primary health care services can be effective in reducing the infant mortality rate (17), and better primary care is associated with reduced rate of new-borns with LBW (18). The content of prenatal care emphasizes on the primary prevention of the risk of preterm birth because this is higher among women who do not receive those services $(15,19)$.

Several studies have shown the effects of the availability of health care practitioners on improving primary care and basic preventive services (20). There is substantial evidence suggesting that increased access to skilled health care staff leads to improvements in health indicators for mothers and new-borns (21-23). The expansion of primary health care, access to family physicians and the implementation of an integrated maternal health program in Brazil were effective in promoting maternal and neonatal health in another study (24).

Some studies conducted in the United States showed that states with a higher density of family physician have better health indices, including a lower rate of LBW infants $(25,26)$. The development of rural midwife programs in Indonesia is associated with an increase in birth weight (27).

After the remarkable success of health care services in reducing mortality and improving fertility in rural areas, in recent years, health care systems of the Islamic Republic of Iran have made fundamental changes in the delivery of medical services in villages and towns with population $<20,000$ (28). In the family physician program, health teams, which include doctors, midwives, behvarzes and other technicians, provide services for 2000-4000 individuals. The teams are responsible for promoting public health, providing primary health care and, if necessary, referring to the next level. After referral to higher levels of expertise, family physicians, and their team are responsible for later follow-ups. All health care services for the population are actively provided by the family physician program and followed up through household visits (28).

Family physician program is held in most of the rural areas in the country, will play an important role in face-toface education and controlling risk factors of LBW (29).
Table 1. Sampling frame in rural area of Kurdistan province in the survey of 2005 and 2013

\begin{tabular}{llll}
\hline District & Health Center & Health & Sample \\
\hline Sanandai & 9 & 16 & 50 \\
Kamyaran & 12 & 33 & 114 \\
Ghorveh & 11 & 22 & 98 \\
Marivan & 7 & 18 & 82 \\
Baneh & 9 & 19 & 90 \\
Saghez & 13 & 33 & 76 \\
Bijar & 10 & 20 & 102 \\
Divandareh & 6 & 15 & 56 \\
Total & 77 & 176 & 668 \\
\hline
\end{tabular}

In order to design and implement appropriate policies to reduce the percentage of LBW infants at the national and local level, it is necessary to assess the factors affecting the incidence of LBW, including the use of human resources to provide preventive services.

Given that, this study was designed and aimed to compare the percentage of LBW infants before and after the implementation of family physician program in health centres with and without changes in midwives density.

\section{Methods}

Data

This quasi-experiment study aimed to determine the effects of recruiting midwives into a family physician program on the percentage of LBW infants. The rural health centres that implemented a family physician program in this study were divided into two groups: health centres that had an increase in their density of midwives during the study's time frame and health centres that had no change in their density of midwives during the same period. The percentage of LBW Infants was compared between participants who sought preventative care for their child at the health centre belonging to one of these two groups. Data collected from mothers who had been referred to the village health houses to vaccinate their 2month-old children.

The unprocessed data that was used as our source of data before establishing the family physician program in 2005 was from the National Plan for Integrated Monitoring and Evaluation Survey (IMES) of Reproductive Health Programs. The researcher collected the data after the implementation of family physician program in 2013. Consistent with the sampling method used for the monitoring and evaluation of reproductive health programs in 2005 , the 2013 sampling was conducted in the same village health houses, using the same sample size (Table 1).

The study sample consisted of 668 mothers who had children $<2$ months old in 2005 and 2013.These mothers were selected from the population of all mothers with 2month-old children who were referred to the village health houses for vaccinations of their 2-month old infants.

The data collection tool for the study in 2013 was a questionnaire used for monitoring and evaluation of reproductive health programs in 2005. An expert committee of the Ministry of Health and Medical Education had tested this questionnaire for validity and reliability in the years 2002-2004 (30). 


\section{Definition of variables}

Based on World Health Organization (WHO)'s definition, LBW defines as a child with birth weight lower than $2500 \mathrm{~g}$ (31). In this study, an illiterate is defined a person who is unable to read or write.

Prenatal complications include the followings: hypertension, premature rupture of membranes, bleeding in the last three months, one-sided swelling of the legs and thighs, blurred vision or headache cause by hypertension, preterm labor, fever, chills, convulsions or loss of consciousness of shocks, bleeding, urinary tract infections, kidney disease, severe and continuous vomiting, poor weight gain, anemia, dental infection, abscesses, severe toothache, preterm delivery, late delivery, gestational diabetes.

Continuity of prenatal care: Delivery of prenatal care for a total of eight times during the pregnancy, delivery of prenatal care for two times up to the 20th week of pregnancy (until the 4th gestational month); delivery of prenatal care for three times at the 26th to 37 th gestational weeks (6, 7 and 8months); delivery of prenatal care for three times at the 38 th to 40 th gestational weeks (9 month).

Standard prenatal care: Prenatal care consistent with the integrated health care services designed for maternal health.

History of high-risk medical conditions include the followings: Diabetes, heart disease, asthma, epilepsy, hypertension, anemia, kidney disease (kidney infection requiring hospitalization), TB.

History of high-risk obstetric conditions include the followings in previous pregnancies (excluding this pregnancy and delivery): Molar pregnancy, ectopic pregnancy, preterm labor, delivered late, stillbirth, miscarriage

The family physician program: family physician program has been started since 2005 as a basic health plan in Iran. At the first step, all residents of villages and towns in the country, with under 20,000 people have to get advantages in equal conditions and comfortable access to health services from this program. For a team of family physicians a population of about 2000 to 4000 people were assigned. Family physician teams consist of: family physician, midwives and other technicians, who were based in rural health centres. Access to family physicians and midwives were possible via referrals from the behvarzes (28).

The village health house is the most peripheral health delivery facility in rural areas and the place from which the behvarz (a formally trained community health worker) works. Each health house is designed to cover a target population of about 1500. Behvarz's services in health house were supported and supervised by family physicians and midwives, who were based in rural health centres (Fig. 1).

The density of rural community health (Behvarz) workers, family physicians or midwives was calculated as the total number of professionals per 1000 persons in the population.

Socioeconomic data: The characteristics of the villages covered by the health centres were collected, including

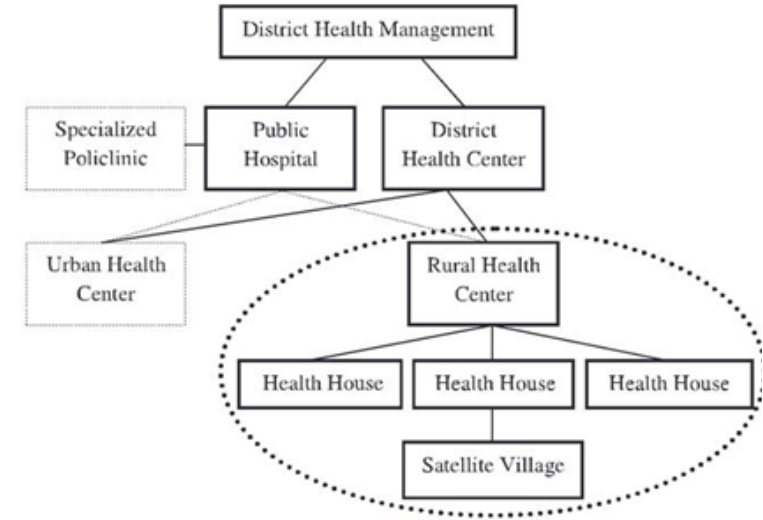

Fig. 1. A simplified structure of PHC network in rural Iran (32)

data on schools, electricity, piped water, gas pipelines, mailboxes, public Internet access and public transportation access and access to newspapers, banks and stores. These data were collected for the years 2005 and 2013. The information about the villages were collapsed at the level of health centres and weighted based on the population of each village. After using principal component analysis (PCA) the percentage of variance explained the first factor reached $\mathrm{Rho}=0.2630$. By removing variables that had high unexplained percentages, the percentage of the variance that explained the first factor reached $\mathrm{Rho}=0.4023$.

\section{Data Analysis}

After completing the questionnaire and checklists, the collected data was analysed using $\mathrm{R}$ and Stata software. To determine the effects of family physician programs on factors associated with caesarean section rates, we used statistical models, including the difference-in-differences model and non-parametric and parametric combined models, of which Matchit was the most appropriate model. We used Matchit model because propensity score matching is a powerful method for to evaluate community-based interventions and clarify the causal relations; it is used when the random implementation of an intervention is neither practical nor ethical. This method can help to reduce selection bias, which is common in observational studies $(33,34)$.

In our study, the intervention was not randomly applied to the health centres, so Matchit was used to show that the changes in the rates of prenatal, postpartum and neonatal complications before and after the intervention had happened under equal conditions.

The final form of difference in difference model was as follows:

$\mathrm{Y} \_\mathrm{icd}=\beta \_0+\beta \_1 \mathrm{~K} \_\mathrm{d}+\beta \_2 \mathrm{~T} \_\mathrm{c}+\beta \_3\left(\mathrm{~K} \_\mathrm{d} * \mathrm{~T} \_\mathrm{c}\right)+\beta \_4$

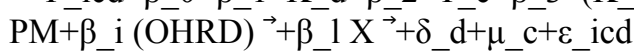

\section{Y: index of LBW}

T: $0=2005 ; 1=2013$

$\mathrm{K}: 0=$ Health centers without increase in their density of midwives; $1=$ Health centers with increase in their density of midwives.

$\mathrm{T}^{*} \mathrm{k}$ : It was equal to 1 when the health centers have increased in their density of midwives in 2013. 
Table 2. Frequencu distribution of the characteristics of the study population by Intervention in family physician program $(2005$ : N=668, 2013: $\mathrm{N}=668)$

\begin{tabular}{|c|c|c|c|c|c|}
\hline \multirow{4}{*}{ Variable } & \multirow{4}{*}{ Category } & \multicolumn{4}{|c|}{$\begin{array}{l}\text { Intervention (increase in the density of midwives)in family physician } \\
\text { program }\end{array}$} \\
\hline & & \multicolumn{2}{|c|}{ Year:2005 } & \multicolumn{2}{|c|}{ Year:2013 } \\
\hline & & Yes & NO & Yes & NO \\
\hline & & $\mathrm{N}(\%)$ & $\mathrm{N}(\%)$ & $\mathrm{N}(\%)$ & $\mathrm{N}(\%)$ \\
\hline \multirow[t]{3}{*}{ Age } & Under 18 years old & $20(71.4)$ & $8(28.6)$ & $8(66.7)$ & $4(33.3)$ \\
\hline & 18 to 35 years old & $470(81.3)$ & $108(18.7)$ & $447(80.4)$ & $109(19.6)$ \\
\hline & Over 35 years old & $47(75.8)$ & $15(24.2)$ & $82(82)$ & $18(18)$ \\
\hline \multirow[t]{2}{*}{ Job } & Employed & 497(79.4) & $129(20.6)$ & $486(80.9)$ & $115(19.1)$ \\
\hline & Unemployed & $40(95.2)$ & $2(4.8)$ & $51(76.1)$ & $16(23.9)$ \\
\hline \multirow[t]{2}{*}{ Education } & Illiterate & 194(77.6) & $56(22.4)$ & $85(80.2)$ & $21(19.8)$ \\
\hline & Literate & $343(82.1)$ & $75(17.9)$ & $452(80.4)$ & $110(19.6)$ \\
\hline \multirow[t]{2}{*}{ Parity } & $\begin{array}{c}\text { High risk }(>=5) \\
\text { pregnancies })\end{array}$ & $41(67.2)$ & $20(32.8)$ & $24(88.9)$ & $3(11.1)$ \\
\hline & $\begin{array}{c}\text { Low risk } \\
(<5 \text { pregnancy })\end{array}$ & $496(81.7)$ & $111(18.3)$ & $513(80)$ & $128(20)$ \\
\hline \multirow[t]{2}{*}{ Smoking or drug abuse } & Yes & $64(74.4)$ & $22(25.6)$ & $29(80.6)$ & $7(19.4)$ \\
\hline & No & $473(81.3)$ & $109(18.7)$ & $508(80.4)$ & $124(19.6)$ \\
\hline History of medical disease or high & Yes & $86(81.1)$ & $20(18.9)$ & $70(85.4)$ & $12(14.6)$ \\
\hline risk obstetrical condition & No & $451(80.2)$ & $111(19.8)$ & $467(79.7)$ & $119(20.3)$ \\
\hline \multirow[t]{2}{*}{ Prenatal complication } & Yes & $218(82.6 \%)$ & $46(17.4)$ & $190(79.2)$ & $50(20.8)$ \\
\hline & No & $319(79)$ & $85(21)$ & $347(81.1)$ & $81(18.9)$ \\
\hline \multirow[t]{2}{*}{ LBW } & Yes & $21(80.8 \%)$ & $5(19.2 \%)$ & $17(85 \%)$ & $3(15 \%)$ \\
\hline & No & $516(80.4 \%)$ & $126(19.6 \%)$ & $520(80.2 \%)$ & $128(19.8 \%)$ \\
\hline \multirow[t]{2}{*}{ Cesarean section } & Yes & $113(77.4)$ & $33(22.6)$ & 181(80.4) & 44(19.6) \\
\hline & No & $424(81.2)$ & $98(18.8)$ & $356(80.4)$ & $87(19.6)$ \\
\hline
\end{tabular}

$b_{3}$ : Mean changes in LBW index in 2013 compared with 2005 in the health centers with increase in their density of midwives compared with the health centers that did not.

$\boldsymbol{X} i$ : Confounding variables such as mother's age, mother's education, density of health workers (Behvarz), density of family physician, population of the village, Sex ratio, Socio-economic status etc were controlled in this study.

To neutralize the effects of random assignment to different districts, the districts of Kurdistan province were entered into the model as indicator variables.

All necessary ethical considerations were honoured in this research. The study was approved by the Research Ethics Committee of the Shahid Beheshti University of Medical Sciences and Health Services and informed consent was obtained from the participants.

\section{Results}

According to the results of a study in 2005 and 2013, $80.8 \%(n=21)$ and $85 \%(n=17)$ of infants who born at a LBW were in health centres that had an increase in their density of midwives during the study's time frame, respectively (Table 2).

About $6.5 \%$ and $33.8 \%$ of the density of midwives were in the fifth quintile in 2005 and 2013 (Table 3).

According to the results of the difference-in-differences model for the intervention (Table 4), there was a decrease in the index of LBW in 2013 compared to $2005, \mathrm{OR}=0.9$ (95\% CI: $0.2-4.6), p=0.9$, even though this is not statistically significant. There was an increase in the index of LBW in 2013 compared to 2005 in health centres where there was an increase in the density of midwives, compared with those health centres that showed no increase , $\mathrm{OR}=1.05$ (95\% CI: $0.16-6.6), \mathrm{p}=0.95$, even though this is not statistically significant.
Concerning the other variables entered into the model, the results showed that the odds ratio of LBW infants increases by more than twice among participants who had a history of the caesarean section, $\mathrm{OR}=2.2$ (95\% CI: 1.16 4.29), $\mathrm{p}=0.01$.

Matchit model showed a significant average percentage increase $0.08(0.006-0.17)$ in LBW infants born between 2005 and 2013 in health centres where the density of midwives increased compared with those where it remained unchanged

\section{Discussion}

The results of this study showed that an increase in the density of midwives in a family physician program did not have an impact on reducing the percentage of LBW infants born between 2005 and 2013, in health centres where the density of midwives augmented compared to those where it remained unaltered.

The result of studies that conducted in Kermanshah province (35) and Qazvin province (36) showed an increase in the prevalence of LBW after implementing family physician program.

In this study according to the results of the differencein-differences model, there was a decrease in the index of LBW in 2013 compared to 2005, even though this is not statistically significant. The study on Mother and Child Health Indices in Rural Population Auspices of Mashhad did not show any significant difference between the mean values of LBW before and after the implementation of a family physician (37).

However, Frankenberg and Thomas (2001) achieved a contrary result in their research; it was shown that the development of rural midwife program in Indonesia is associated with an increase in birth weight (27). Women who 
Table 3. Density of midwives, family physicians and Behvarzes in health centers in the survey of 2005 and 2013

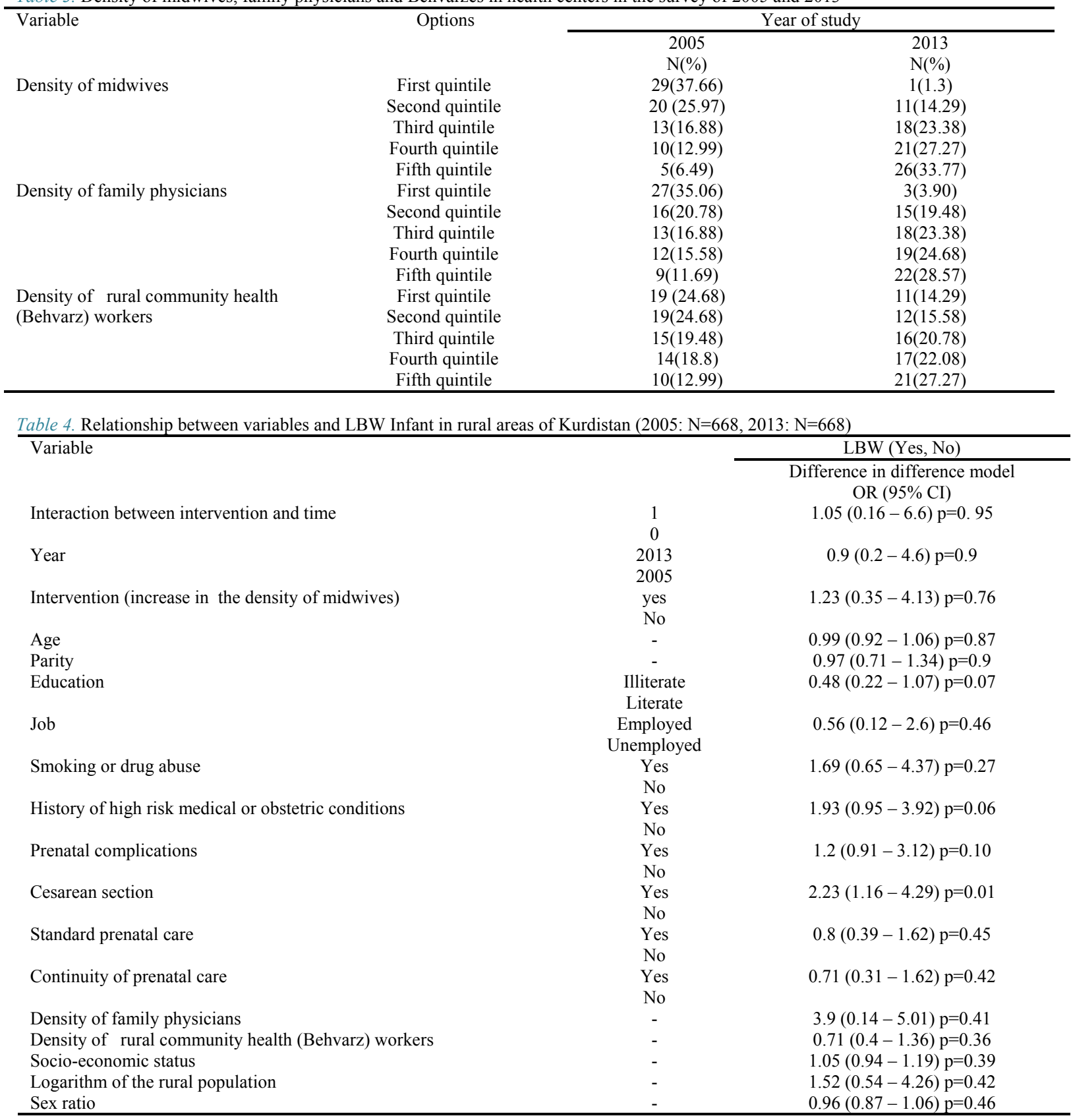

participated in St. Louis program, compared with matched and unmatched groups, had lower rates of preterm and LBW infants (38). A study conducted by Vogel and Ackerman showed that increasing number of family physicians and delivering primary care services is associated with a reduction in LBW rate (26). Some studies conducted in the United States showed that states with a higher density of family physician, even after controlling for socioeconomic and demographic variables, have better health indices, including lower LBW rate $(25,26)$.

Also, in this study, the odds ratio of LBW infants increased by more than twice among participants who had a history of caesarean section. One of the causes of LBW is preterm delivery, which may be due to early elective caesarean section followed by maternal or foetal indications
(5-6,39).

The results of a cohort study in Brazil showed that after controlling for some confounding factors, there is a statistically significant association between caesarean delivery and LBW (40). Overall, recent studies reported serious concerns about a possible link between caesarean section and LBW or preterm birth (40). There are still many cases of unnecessary caesarean section (41). The results of our study showed an increase in the risk of LBW infants due to caesarean section. It is recommended that obstetricians and gynaecologists must be recommended to strictly control pregnancies and avoid unnecessary termination of pregnancy.

In this study, the results of difference in difference model showed that continuity of prenatal care and mater- 
nal care by defined standards leads to a reduction in the percentage of LBW infants, even though this is not statistically significant. Results of a study in Ardestan showed that the percentage of LBW infants and preterm delivery in the group that received integrated maternal health care services were lower than the other group (42).

In this study, the results of difference in difference model showed that history of high-risk medical or obstetric conditions, prenatal complications and smoking or drug abuse leads to an increase in the percentage of LBW infants, even though this is not statistically significant. Some studies showed that smoking (9), hypertension, and genitourinary tract infection in pregnancy are determinants of LBW (14).

There is much evidence showing that increased access to skilled manpower directly leads to improved maternal and neonatal health indicators (21-22,43-44). However, the results of this study showed that an increase in the density of midwives in a family physician program did not have an impact on reducing the percentage of LBW infants born between 2005 and 2013, in health centres where the density of midwives augmented compared to those where it remained unaltered; it indicated that the increase in the density of staff alone was insufficient. In other words, the quality of primary health care is strongly dependent on the use of trained health workers. Also, manpower planning and management can have an important role in the improvement of prenatal care.

Overall, several studies have examined the associations between human resources and health indicators, finding contradicting results: some have reported positive associations between these constructs, while others have reported negative association $(27,45-49)$ The results of these previous studies are influenced by various factors. For instance, many of these studies did not assess the effects of health worker density on health indicators at the individual level, but they calculated health indicators at the level of district, province or country. The relationship between the variables in a district may not reflect the relationship between variables at the individual level. In addition, these studies did not take into account the socioeconomic status at the individual or family level, and preferring instead to use variables such as the average level of education within a district, although the socioeconomic statuses of individuals are a preferred measure that can increase the precision of the study. Nevertheless, the measurement of cumulative socioeconomic variables is valid at the district level (50). In many of these studies, there is no data about the actual use of family physician services by each individual (51).

One of the strengths of the present study is that the data were collected at individual level; another is the use of Matchit statistical model. A third strength of this study is that it compared the services received by mothers with pre-defined standards proposed by the Ministry of Health and Medical Education, assessed the services and evaluated the consistency between the services provided and the standard services. It showed how closely service providers are following the standards when providing primary health care services. The study was limited by the fact that we only had two time points for data collection, in 2005 and
2013, and therefore, we were unable to show changes occurring during these years. Moreover, confounding variables such as poor maternal nutritional status, non-pregnant weight, intervals between pregnancies and violence during pregnancy were not controlled in this study.

\section{Conclusion}

The results of this study showed that an increase in the density of midwives in a family physician program did not have an impact on reducing the percentage of LBW infants; it indicated that the increase in the density of midwives alone was not efficient.

Strong governmental policies and financial support are very important factors needed for a community-based intervention program. On the other hand, intervention strategies should include comprehensive programs for technical support, manpower training, health education and community mobilization and participation, all of which are equally important.

Certainly, without skilled manpower in the right time and place, it is not possible to achieve the goals of health for all, primary health care objectives and objectives set by the Sustainable Development Goals (SDGs). This means that increasing in the density of manpower alone will not be effective. The quality of primary health care services highly depends on the use of trained health care staff. Human resource planning and management can have an important role in the improvement of prenatal care. Therefore, monitoring and evaluation of inputs, including human resources, processes, and outputs of health systems are necessary to identify barriers or facilitators to achieve the SDGs for maternal health.

On the other hand, the results of our study show an increase in the risk of infants born at a LBW due to caesarean section. It is recommended that obstetricians and gynaecologists must strictly control pregnancies and avoid unnecessary termination of pregnancy.

\section{Acknowledgements}

The authors would like to thank the Ministry of Health and Medical Education, Research, deputy of Shahid Beheshti University of Medical Sciences, Health deputy of Kurdistan University of Medical Sciences for their supports. It is worth mentioning that this study was part of a Ph.D. thesis on Reproductive Health which was conducted by Shayesteh Hajizadeh |(Ph.D. student of Reproductive Health, School of Nursing and Midwifery, Shahid Beheshti University of Medical Sciences).

\section{Conflict of interests}

The authors declare that they have no competing interests.

\section{References}

1. UNICEF. United Nations Children's Fund and World Health Organization, Low Birthweight: Country, regional and global estimates. New York: UNICEF 2004.

2. Paneth NS. The problem of low birth weight. Future Child 1995:19-34. 
3. Victora CG, Barros FC, Huttly SR, Teixeirae AMB, Vaughan JP. Early childhood mortality in a Brazilian cohort: the roles of birthweight and socioeconomic status. Int. J. Epidemiol 1992; 21(5):911-5.

4. Kaijser M, Bonamy AKE, Akre O, Cnattingius S, Granath F, Norman M, et al. Perinatal Risk Factors for Ischemic Heart Disease Disentangling the Roles of Birth Weight and Preterm Birth. Circulation 2008;117(3):405-10.

5. Silva A, Barbieri M, Gomes U, Bettiol H. Trends in low birth weight: a comparison of two birth cohorts separated by a 15year interval in Ribeirao Preto, Brazil. Bull. World Health Organ 1998;76(1):73.

6. Goldenberg RL, Culhane JF, Iams JD, Romero R. Epidemiology and causes of preterm birth. The lancet 2008;371(9606):75-84.

7. Babaei Gh, Keshavarz M, Parsinia M, Ashkvari P. Evaluation of effective factors on low birth weight neonates' mortality using path analysis. TUMJ 2008;66(1):52-6.

8. Tayebi T, Zahrani ST, Mohammadpour R. Relationship between adequacy of prenatal care utilization index and pregnancy outcomes. Iran $\mathrm{J}$ Nurs Midwifery Res 2013;18(5):360.

9. Mumbare SS, Maindarkar G, Darade R, Yenge S, Tolani MK, Patole K. Maternal risk factors associated with term low birth weight neonates: a matched-pair case control study. Indian J Pediatr 2012;49(1):25-8.

10. Blumenshine P, Egerter S, Barclay CJ, Cubbin C, Braveman PA. Socioeconomic disparities in adverse birth outcomes: a systematic review. Am J Prev Med 2010;39(3):263-72.

11. Li C, Sung F. Socio-economic inequalities in low-birth weight, full-term babies from singleton pregnancies in Taiwan. Public health 2008; 122(3):243-50.

12. Muula A, Siziya S, Rudatsikira E. Parity and maternal education are associated with low birth weight in Malawi. Afr J Health Sci 2011;11(1).

13. Viengsakhone L, Yoshida Y, Sakamoto J. Factors affecting low birth weight at four central hospitals in vientiane, Lao PDR. Nagoya J Med Sci 2010;72(1-2):51-8.

14. Moraes ABd, Zanini RR, Riboldi J, Giugliani ERJ. Risk factors for low birth weight in Rio Grande do Sul State, Brazil: classical and multilevel analysis. Cad Saude Publica 2012; 28(12):2293-305.

15. Iams JD, Romero R, Culhane JF, Goldenberg RL. Primary, secondary, and tertiary interventions to reduce the morbidity and mortality of preterm birth. The lancet 2008;371(9607):164-75.

16. Pickett KE, Pearl M. Multilevel analyses of neighbourhood socioeconomic context and health outcomes: a critical review. J Epidemiol Community Health 2001;55(2):111-22.

17. Macinko J, Starfield B, Shi L. The contribution of primary care systems to health outcomes within Organization for Economic Cooperation and Development (OECD) countries, 1970-1998. Health Serv. Res 2003;38(3):831-65.

18. Starfield B, Shi L. Policy relevant determinants of health: an international perspective.J Health policy 2002;60(3):201-18.

19. Healy AJ, Malone FD, Sullivan LM, Porter TF, Luthy DA, Comstock $\mathrm{CH}$, et al. Early access to prenatal care: implications for racial disparity in perinatal mortality. AM J OBSTET GYNECOL 2006;107(3):625-31.

20. Shi L, Starfield B. Primary care, income inequality, and selfrated health in the United States a mixed-level analysis. Int. J. Health Serv 2000;30(3):541-56.

21. Anand S, Bärnighausen T. Health workers and vaccination coverage in developing countries: an econometric analysis. The Lancet 2007; 369(9569):1277-85.

22. Anand S, Bärnighausen T. Human resources and health outcomes: cross-country econometric study. The Lancet 2004;364(9445):1603-9.

23. Sousa A, Tandon A, Dal Poz MR, Prasad A, Evans DB. Measuring the efficiency of human resources for health for attaining health outcomes across subnational units in Brazil. World Health Organ Tech Rep Ser 2006.

24. Cesar JA, Matijasevich A, Santos IS, Barros AJ, Dias-daCosta JS, Barros FC, et al. The use of maternal and child health services in three population-based cohorts in Southern Brazil ,1982-2004. Cad Saude Publica 2008;24:s427-s36.

25. Shi L, Stevens GD, Wulu JT, Politzer RM, Xu J. America's Health Centers: reducing racial and ethnic disparities in perinatal care and birth outcomes. Health Serv Res 2004;39(6p1):1881-902.

26. Vogel RL, Ackermann RJ. Is primary care physician supply correlated with health outcomes? Int J Health Serv 1998;28(1):183-96

27. Frankenberg E, Thomas D. Women's health and pregnancy outcomes: Do services make a difference? Demography 2001;38(2):253-65.

28. Ministry of Health and Medical Education. Operational guide for family physician project implementation. In: Ministry of Health and Medical Education., editor. Tehran 2012. [Persian].

29. Baghianimoghadam M, Baghianimoghadam B, Ardian N, Alizadeh E. Risk factors of low birth weight and effect of them on growth pattern of children up to sixth months of life: A cross-sectional study. J Educ Health Promot 2015; 4(1):40.

30. Ministry of Health and Medical Education. Report of the survey, monitoring and evaluation of reproductive health programs in Iran. Tehran: Ministry of Health and Medical Education 2008. [Persian].

31. GML. Dictionary of epidemiology. Shojaee H, Malekafzali H, editors. 4th ed. Vol. 2. Tehran, Iran: Samat Publication 2004. pp. 230-45.

32. Takian A, Doshmangir L, Rashidian A. Implementing family physician programme in rural Iran exploring the role of an existing primary health care network. Fam Med 2013:cmt025.

33. Jiang M, Foster EM, Gibson-Davis CM. Breastfeeding and the child cognitive outcomes: a propensity score matching approach. Matern Child Health J 2011;15(8):1296-307.

34. Harder VS, Stuart EA, Anthony JC. Propensity score techniques and the assessment of measured covariate balance to test causal associations in psychological research. Psychol Methods 2010;15(3):234.

35. Taha Z, Vahdat S. The Effect of Implementing Family Physician Program on Health Indices in Kermanshah Province. IJRLS 2015; 5(5):1319-25.

36. Mansourian M, Rastgari Mehr B, Kalantari Z, Mahram M, Hosainzadeh Milani M, Shafieyan Z, et al. The Effect of family physician program on health indicators in rural population of Qazvin province, 2004-2010. RJMS 2014;21(126):27-32.

37. Raeissi P, Ebadi Fard Azar F, Roudbari M. The Impact of Family Physician Program on Mother and Child Health Indices in Rural Population Auspices of Mashhad University of Medical Sciences and Health Care Services, Iran; 2009. J Health Adm 2011;14(43):27-36.

38. Cooper BP, Scharff DP, Elliott M, Rotter B. The impact of SLHS Program on perinatal indicators. Matern Child Health J 2013;17(6):1158-65.

39. Villar J, Valladares E, Wojdyla D, Zavaleta N, Carroli G, Velazco A, et al. Caesarean delivery rates and pregnancy outcomes: the 2005 WHO global survey on maternal and perinatal health in Latin America. The Lancet 2006;367(9525):1819-29. 
40. Silva AA, Lamy-Filho F, Alves MT, Coimbra LC, Bettiol H, Barbieri MA. Risk factors for low birthweight in north-east Brazil: the role of caesarean section. Paediatr Perinat Epidemiol 2001;15(3):257-64.

41. Veloso HJ, da Silva AA, Bettiol H, Goldani MZ, Lamy Filho F, Simões VM, et al. Low birth weight in São Luís, northeastern Brazil: trends and associated factors. BMC pregnancy and childbirth 2014;14(1):155.

42. Roohparvarzadeh N, Shahidi S. Effect of standardizing prenatal care protocol on pregnancy outcome Iran J Nurs Midwifery Res 2008;12(2).

43. Speybroeck N, Kinfu Y, Dal Poz MR, Evans DB. Reassessing the relationship between human resources for health, intervention coverage and health outcomes. Geneva, WHO 2006.

44. Gupta N, Maliqi B, França A, Nyonator F, Pate MA, Sanders $D$, et al. Human resources for maternal, newborn and child health: from measurement and planning to performance for improved health outcomes. Hum Resour Health 2011;9(1):16.

45. Piérard E. The effect of physician supply on health status as measured in the NPHS. University of Waterloo, Department of Economics 2009.

46. Busato A, Künzi B. Primary care physician supply and other key determinants of health care utilisation: the case of Switzerland. BMC Health Serv. Res. 2008;8(1):8.

47. Needleman J, Buerhaus P, Mattke S, Stewart M, Zelevinsky K. Nurse-staffing levels and the quality of care in hospitals. N. Engl. J. Med 2002;346(22):1715-22.

48. Gulliford MC. Availability of primary care doctors and population health in England: is there an association? Am J Public Health Res 2002; 24(4):252-4.

49. Farzadfar F ,Murray CJ, Gakidou E, Bossert T, Namdaritabar $\mathrm{H}$, Alikhani S, et al. Effectiveness of diabetes and hypertension management by rural primary health-care workers (Behvarz workers) in Iran: a nationally representative observational study. The Lancet 2012; 379(9810):47-54.

50. Ferrante JM, Gonzalez EC, Pal N, Roetzheim RG. Effects of physician supply on early detection of breast cancer. J Am Board Fam Pract 2000; 13(6):408-14.

51. Campbell RJ, Ramirez AM, Perez K, Roetzheim RG. Cervical cancer rates and the supply of primary care physicians in Florida. Fam Med 2003;35(1):60-7. 